\title{
Editorial
}

\section{Leading Progress in Digital Terrain Analysis and Modeling}

\author{
Giulia Sofia ${ }^{1, *(\mathbb{O})}$, Anette Eltner ${ }^{2}(\mathbb{D})$, Efthymios Nikolopoulos ${ }^{3}\left(\mathbb{C}\right.$ ) and Christopher Crosby ${ }^{4}$ \\ 1 Department of Civil and Environmental Engineering, University of Connecticut, Storrs, CT 06269, USA \\ 2 Institute of Photogrammetry and Remote Sensing, Technische Universität, 01069 Dresden, Germany \\ Department of Mechanical and Civil Engineering, Florida Institute of Technology, Melbourne, FL 32901, USA \\ 4 UNAVCO, Boulder, CO 80301, USA \\ * Correspondence: giulia.sofia@uconn.edu
}

Received: 13 August 2019; Accepted: 21 August 2019; Published: 27 August 2019

\begin{abstract}
Digital Terrain analysis (DTA) and modeling has been a flourishing interdisciplinary field for decades, with applications in hydrology, geomorphology, soil science, engineering projects and computer sciences. Currently, DTA is characterized by a proliferation of multispectral data from new sensors and platforms, driven by regional and national governments, commercial businesses, and scientific groups, with a general trend towards data with higher spatial, spectral or temporal resolutions. Deriving meaningful and interpretable products from such a large pool of data sources sets new challenges. The articles included in this special issue (SI) focuses on terrain analysis applications that advance the fields of hydrology, geomorphology, soil science, geographic information software (GIS), and computer science. They showcase challenging examples of DTA tackling different subjects or different point of views on the same subject.
\end{abstract}

Keywords: geomorphometry; topography; digital elevation model; digital terrain model

\section{Introduction}

Digital Terrain analysis (DTA) and modeling has been a flourishing interdisciplinary field for decades, with applications in hydrology, geomorphology, soil science, engineering projects and computer sciences [1-13]. DTA is not so much a single technique, but rather a set of multiple algorithms developed from theory and principles of earth and planetary science, mathematics, and computer science.

Currently, DTA is characterized by a proliferation of multispectral data from new sensors and platforms, driven by regional and national governments, commercial businesses, and scientific groups, with a general trend towards data with higher spatial, spectral or temporal resolutions [14]. Advances in remote sensing, satellite imaging, and computing technology, together with the availability of open data [15-20] have enabled scientists to access topographic information with unprecedented resolution and complexity [3,5,21], and global scales [22-24]. The challenge is now the interpretation of surface morphology to improve our understanding of geomorphic processes from micro to global scales. Thus, deriving meaningful and interpretable products from such a large pool of data sources sets new challenges.

The articles included in this special issue (SI) focuses on terrain analysis applications that advance the fields of hydrology, geomorphology, soil science, GIS, and computer science. They showcase challenging examples of DTA tackling different subjects or different point of views on the same subject.

A first group of papers refer to depressions and flat areas on Digital Elevation Models (DEMs). A hydrologically correct DEM forms a basis for realistic environmental modelling, especially in complex terrain. It involves the creation of a surface that can host a continuous, integrated drainage 
network. The corresponding two papers, highlight two contrasting but complementary issues on this subject. Historically, depressions and flat surfaces in DEMs have been viewed as data errors. However, the rapid expansion of high-resolution, high-precision DEM coverage increases the likelihood that depressions are real-world features. These are an important part of the hydrologic system, and should be represented and identified.

On the one hand, considering the removal of DEMs artifacts, the paper by [25] proposes a new algorithm for enhanced flat surface removal. Their application showed that the new algorithm effectively corrected elevations of small, insignificant depressions and flats (e.g., artifacts), and improved the efficiency of surface delineation.

On the other hand, the work by [26] focuses on DEM depressions as an important landscape feature, which should not be removed. Their work considers karst depressions and highlights how the morphological characteristics of these type of depressions reflects the development and evolution of karst landforms. Their work proposes a method to automatically extract these features. The introduced methodology can accurately determine the boundary of each depression and provide an important reference database for quantitative research in karst landforms.

The second group of papers in the SI tackle roughness analysis. Surface roughness is a key variable used across the earth and planetary sciences to both identify individual landforms and determine the processes acting upon them. Generally, the term surface roughness is used as an expression of the variability of elevation of a topographic surface at a given scale, where the scale of analysis is determined by the size of the landforms or geomorphic features of interest, either local or regional. In this SI, two works deal with the influence of scale in roughness analysis but from different points of view: to identify the optimal wavelength of lidar data [27], and to derive gray-level co-occurrence matrices focus on the roughness spectrum [27,28], a derivative of digital terrain models (DTMs) that is used as a surface roughness descriptor in many geomorphological and physical models. Their work assesses differences in such spectra due to different sources of lidar point clouds or due to different processing of the same point cloud. Considering terrestrial laser scanning (TLS), and laser scanning from both an uncrewed aerial vehicle and an airplane, they identify the scale (spatial wavelengths) over which the analyzed spectra can be used interchangeably.

From a textural perspective, [28] refer to roughness by the use of the gray-level co-occurrence matrix. Their work proposes a new approach for quickly determining the multi-scale parameters of such texture, with the assistance of a geographic information system and domain knowledge. The proposed method can reduce classification uncertainties, as well as better meet the requirements of large-scale image geo-analysis.

Related to texture and scale, the problem of visualizing 3D data correctly is analyzed by [29]. DTA applications all require visualizing the relationship between terrain and objects located in geographic space. However, creating suitable representations is challenging. Conveying the details of terrain models is difficult, due to the complexity of the data under analysis, and computational restraints. To add challenges, representing spatial data at multiple scales within the same scene increases the complexity of the resulting images, and produces cluttered outputs, [29] provide an approach to demonstrate how features in the terrain can be visualized appropriately. They offer a concept to effectively communicate local and global features of 3D terrain and geo-spatial data, and they illustrate a software framework that enables real-time rendering and design of sophisticated terrain visualizations.

The third group of papers showcases the integration of different sources of data to perform DTA. They identify challenges and limitations, and propose improved methods of analysis. Work by [30] addresses problems arising from the use of data acquired with two different remote sensing techniques-high-resolution satellite imagery and TLS-data for the creation of DEMs in the context of landslide recognition. They highlight challenges and the demands of processing satellite and TLS data to obtain georeferenced point clouds, and they provide uncertainty maps to highlight differences. They further showcase comparative analysis of selected landslide features drawn from the two data 
sources, identifying the optimal solution. Work by [31] focus on vertical accuracy of DEMs from lidar and photogrammetry. They propose an analysis that evaluates the accuracy of both models in relation to vegetation presence, and highlight the challenges and limitations of using photogrammetry in vegetated areas.

Finally, a workflow is introduced that integrates classical techniques for soil erosion assessment with photogrammetry to map the current soil surface level and to improve the accuracy of estimating long-term soil mobilization rates in vineyards [32]. For this work, the authors highlight how camera pictures can aid the observation of the impacts of erosion factors in vineyards, such as tillage erosion, and runoff pathway detection.

Digital terrain analysis has revolutionized the way topography is characterized and analyzed. Its applicability has widened to almost anything where topography has a role to play. The current technological push towards higher resolution might even exceed the requirements for landform description/classification, process characterization, and the exploration of linkages between landforms and processes. However, the utility of these new and higher resolution topographic datasets in earth and planetary sciences requires that scientists continue to develop new he tools and analysis approaches to answer the questions that motivate current research priorities. While DTA attracts many researchers including geographers, surveyors, engineers, and computer scientists, the potential lack of communication across disciplines results in efforts to be mainly focused on problems within individual fields of application.

The future of the field relies on fostering collaboration and sharing ideas across subject/disciplineboundaries, between technique developers and users, enabling us as a community to fully exploit the wealth of knowledge inherent in our digital landscape.

Author Contributions: All authors substantially contributed to this editorial.

Funding: This research received no external funding.

Conflicts of Interest: The authors declare no conflict of interest.

\section{References}

1. Clarke, K.C.; Romero, B.E. On the Topology of Topography: A Review. Cartogr. Geogr. Inf. Sci. 2017, 44, 271-282. [CrossRef]

2. Deng, Y. New trends in digital terrain analysis: Landform definition, representation, and classification. Prog. Phys. Geogr. Earth Environ. 2007, 31, 405-419. [CrossRef]

3. Sofia, G.; Hillier, J.K.; Conway, S.J. Frontiers in Geomorphometry and Earth Surface Dynamics: Possibilities, limitations and perspectives. Earth Surf. Dyn. 2016, 4, 721-725. [CrossRef]

4. Wilson, J.P.; Gallant, J. Terrain Analysis: Principles and Applications; Wilson, J.P., Gallant, J.C., Eds.; John Wiley and Sons, Inc.: New York, NY, USA, 2000.

5. Sofia, G. Combining Geomorphometry, Feature Extraction Techniques and Earth-Surface Processes Research: The Way Forward. Geomorphology. under review.

6. Florinsky, I.V. Combined analysis of digital terrain models and remotely sensed data in landscape investigations. Prog. Phys. Geogr. Earth Environ. 1998, 22, 33-60. [CrossRef]

7. Florinsky, I.V. An illustrated introduction to general geomorphometry. Prog. Phys. Geogr. Earth Environ. 2017, 41, 723-752. [CrossRef]

8. Hengl, T.; Reuter, H.I. (Eds.) Geomorphometry: Concepts, Software, Applications; Elsevier: Amsterdam, The Netherlands, 2008; Volume 33.

9. Lecours, V.; Dolan, M.F.J; Micallef, A.; Lucieer, V.L. A review of marine geomorphometry, the quantitative study of the seafloor. Hydrol. Earth Syst. Sci. 2016, 20, 3207-3244. [CrossRef]

10. Li, Z.; Zhu, Q.; Gold, C. Digital Terrain Modeling: Principles and Methodology; CRC Press: Boca Raton, FL, USA, 2005.

11. Moore, I.D.; Grayson, R.B.; Ladson, A.R. Digital Terrain Modelling: A Review of Hydrological, Geomorphological, and Biological Applications. Hydrol. Process. 1991, 5, 3-30. [CrossRef] 
12. Peckham, R.; Jordan, G. (Eds.) Best Practice in Digital Terrain Modelling: Development and Applications in a Policy Support Environment; Springer: Berlin/Heidelberg, Germany, 2007.

13. Pike, R.J. Geomorphometry-diversity in quantitative surface analysis. Prog. Phys. Geogr. Earth Environ. 2000, 24, 1-20.

14. Smith, M.; Pain, C.; Pain, C.; Smith, M. Applications of remote sensing in geomorphology. Prog. Phys. Geogr. Earth Environ. 2009, 33, 568-582. [CrossRef]

15. Bocher, E.; Neteler, M. (Eds.) Geospatial Free and Open Source Software in the 21st Century; Lecture Notes in Geoinformation and Cartography; Springer: Berlin/Heidelberg, Germany, 2012.

16. Crosby, C. OpenTopography: Enabling Online and On-Demand Access to High-Resolution Topography Data for Natural Hazards. In Geomorphometry for Geosciences; Jasiewicz, J., Zwoliński, Z., Mitasova, H., Hengl, T., Eds.; Bogucki Wydawnictwo Naukowe, Adam Mickiewicz University in Poznań-Institute of Geoecology and Geoinformation: Poznań, Poland, 2015.

17. Krishnan, S.; Crosby, C.; Nandigam, V.; Phan, M.; Cowart, C.; Baru, C.; Arrowsmith, R. OpenTopography: A Services Oriented Architecture for Community Access to LIDAR Topography. Proceedings of the 2Nd International Conference on Computing for Geospatial Research E Applications, Washington, DC, USA, 23-25 May 2011; ACM Press: New York, NY, USA, 2011; article n. 7.

18. Woodcock, C.E.; Allen, R.; Anderson, M.; Belward, A.; Bindschadler, R.; Cohen, W.; Gao, F.; Goward, S.N.; Helder, D.; Helmer, E.; et al. Free Access to Landsat Imagery. Science 2008, 320, 1011. [CrossRef] [PubMed]

19. Wulder, M.A.; Masek, J.G.; Cohen, W.B.; Loveland, T.R.; Woodcock, C.E. Opening the archive: How free data has enabled the science and monitoring promise of Landsat. Remote Sens. Environ. 2012, 122, 2-10. [CrossRef]

20. Tarolli, P.; Sofia, G.; Ellis, E. Mapping the Topographic Fingerprints of Humanity across Earth. EOS 2017, 98. [CrossRef]

21. Eltner, A.; Kaiser, A.; Castillo, C.; Rock, G.; Neugirg, F.; Abellán, A. Image-based surface reconstruction in geomorphometry-Merits, limits and developments. Earth Surf. Dyn. 2016, 4, 359-389. [CrossRef]

22. Takaku, J.; Tadono, T.; Tsutsui, K.; Ichikawa, M. Validation of "AW3D\&quot" Global DSM Generated from Alos Prism. ISPRS Ann. Photogramm. Remote Sens. Spat. Inf. Sci. 2016, 3, 25.

23. Wasowski, J.; Bovenga, F.; Nutricato, R.; Nitti, D.O.; Chiaradia, M.T. High Resolution Satellite SAR Multi Temporal Interferometry for Regional Scale Detection of Landslide and Subsidence Hazards. In Geomorphometry for Geosciences; Jasiewicz, J., Zwoliński, Z., Mitasova, H., Hengl, T., Eds.; Bogucki Wydawnictwo Naukowe, Adam Mickiewicz University in Poznań-Institute of Geoecology and Geoinformation: Poznań, Poland, 2015; pp. 181-184.

24. Purinton, B.; Bookhagen, B. Validation of digital elevation models (DEMs) and comparison of geomorphic metrics on the southern Central Andean Plateau. Earth Surf. Dyn. Discuss. 2017, 5, 211-237. [CrossRef]

25. Liu, X.; Wang, N.; Shao, J.; Chu, X. An Automated Processing Algorithm for Flat Areas Resulting from DEM Filling and Interpolation. ISPRS Int. J. Geo Inf. 2017, 6, 376. [CrossRef]

26. Yang, X.; Tang, G.; Meng, X.; Xiong, L. Saddle Position-Based Method for Extraction of Depressions in Fengcong Areas by Using Digital Elevation Models. ISPRS Int. J. Geo Inf. 2018, 7, 136. [CrossRef]

27. Milenković, M.; Ressl, C.; Karel, W.; Mandlburger, G.; Pfeifer, N. Roughness Spectra Derived from Multi-Scale LiDAR Point Clouds of a Gravel Surface: A Comparison and Sensitivity Analysis. ISPRS Int. J. Geo Inf. 2018, 7,69. [CrossRef]

28. Lan, Z.; Liu, Y. Study on Multi-Scale Window Determination for GLCM Texture Description in High-Resolution Remote Sensing Image Geo-Analysis Supported by GIS and Domain Knowledge. ISPRS Int. J. Geo Inf. 2018, 7, 175. [CrossRef]

29. Dübel, S.; Schumann, H. Visualization of Features in 3D Terrain. ISPRS Int. J. Geo Inf. 2017, 6, 357. [CrossRef]

30. Barbarella, M.; Di Benedetto, A.; Fiani, M.; Guida, D.; Lugli, A. Use of DEMs Derived from TLS and HRSI Data for Landslide Feature Recognition. ISPRS Int. J. Geo Inf. 2018, 7, 160. [CrossRef]

31. Salach, A.; Bakuła, K.; Pilarska, M.; Ostrowski, W.; Górski, K.; Kurczyński, Z. Accuracy Assessment of Point Clouds from LiDAR and Dense Image Matching Acquired Using the UAV Platform for DTM Creation. ISPRS Int. J. Geo Inf. 2018, 7, 342. [CrossRef] 
32. Remke, A.; Rodrigo-Comino, J.; Gyasi-Agyei, Y.; Cerdà, A.; Ries, J.B. Combining the Stock Unearthing Method and Structure-from-Motion Photogrammetry for a Gapless Estimation of Soil Mobilisation in Vineyards. ISPRS Int. J. Geo Inf. 2018, 7, 461. [CrossRef]

(C) 2019 by the authors. Licensee MDPI, Basel, Switzerland. This article is an open access article distributed under the terms and conditions of the Creative Commons Attribution (CC BY) license (http://creativecommons.org/licenses/by/4.0/). 